\title{
BRUSH/SLIP RING CURRENT COLLECTOR PERFORMANCE AND ANOMALIES DURING COMPULSATOR COMMISSIONING
}

\author{
By: \\ J.J. Hahne \\ J.R. Kitzmiller \\ C.E. Penney
}

10th EML Symposium, April 25-28, 2000, San Francisco, CA, pp. 302-304

IEEE Transactions on Magnetics, vol. 37 no. 1, January 2001

PR - 274

Center for Electromechanics

The University of Texas at Austin

PRC, Mail Code R7000

Austin, TX 78712

(512) 471-4496 


\title{
Brush/Slip Ring Current Collector Performance and Anomalies During Compulsator Commissioning
}

\author{
Jonathan J. Hahne, Jonathan R. Kitzmiller, and Charles E. Penney \\ The University of Texas at Austin Center for Electromechanics
}

\begin{abstract}
During recent tests associated with a model scale compulsator development program at The University of Texas at Austin Center for Electromechanics (UT-CEM), the performance of severe duty trailing arm brush current collectors was evaluated. The original material of choice for the brush slip ring design was 70075-T6 aluminum to minimize machine mass and simplify slip ring assembly on the rotor shaft. The slip rings have a nominal diameter of $5.5 \mathrm{in}$. The combination of CM1S copper, trailing arm brushes, and aluminum slip rings performed well up to about $80 \%$ full speed, although the design did not appear to be very damage tolerant. As testing continued at higher speeds, one of the slip rings began to exhibit small shallow arc pits in the brush track on the slip ring outer diameter. This was observed on only one slip ring and had no apparent affect on machine performance. Left unchecked, this shallow arc damage can cause a high speed brush to "bounce" excessively during a run and cause more severe damage, as well as increase the circuit impedance from the arcing.

This paper presents a general description of the observed brush performance during normal and fault conditions. It also includes a description of mechanical analysis and field strength measurements done around the brushes in an effort to explain the "one brush" bouncing. Brush and slip ring design upgrades (including a reinforced brush actuator for increased brush down-force and a newly implemented two-layer aluminum and steel slip ring design) will be discussed.
\end{abstract}

\section{INTRODUCTION}

$\mathrm{D}$ URING recent testing of a model scale compulsator system, a unique problem was encountered in the brush performance. This model scale compulsator utilized a rotating field coil design with a set of brushes on the end of one shaft to deliver power to the field coil for machine excitation. Each set of brushes (one positive and one negative) utilized six trailing arm brushes evenly distributed around the shaft (Fig. 2). Each set of brushes ran on a 7075T6 aluminum slip ring with a nominal OD of 5 in. During lower speed testing ( $<80 \%$ full speed) the brushes performed well with no observed problems. However, at speeds over $80 \%$ full speed, the OD of the outer slip ring showed evidence of small arcs and pitting while the inner slip ring surface remained in good condition throughout the testing. These arc marks were randomly distributed around the circumference of the shaft; they varied in size from 0.10 to

Manuscript received December 21, 1999. Funding for this research was provided by the U.S. Army under contract DAAA21-92-C-0105.
0.25 in. in diameter; and they were generally less than 0.003 to 0.005 in. deep (Fig. 3). These arc marks were round in shape and were generally located along the edges of the brush track left on the aluminum slip ring. Observations of the brush pads themselves showed small areas of arc damage around the contact surface of the brush pads. A unique feature of these arc marks was how round they were, as one would expect an arc occurring in an interface spinning at high speed to be elongated from the shaft rotation. The arc pits were also relatively shallow. The damage was generally cleaned up between tests with a light sanding operation on the aluminum slip ring.

This problem had never been observed on other rotating electrical machines at UT-CEM. The question remained as to why one set of brushes would arc and the other would not when they are running at the same relative surface speed, conducting the same current, and with the same down force. The problem might be traced to a mechanical or electrical source, or to a combination of the two. The first theory was that speeds over $80 \%$ full speed caused a mechanical problem at the brush/slip ring interface. The second theory was that as the machine speed increases, the field coil current goes up and initiates some type of electrical problem. Initial evaluation of the design showed this brush system was operating well within demonstrated mechanical and electrical performance values.

\section{MECHANICAL EVALUATION}

The total down force on an individual brush can be defined as the applied force from the pneumatically actuated bladder plus the electromagnetic load from the compensated brush strap. The force from the actuator is a constant, regardless of machine speed. For the brush system in question, an applied actuation pressure of 90-95 psi produced a relatively constant $18 \mathrm{lb}$ of down force on each brush; however, the electromagnetic loading from the brush strap compensation varies with field coil current. The compensation force on the brush straps was approximated using a procedure for calculating the repulsion force between strap conductors [4]. Combining the mechanical down force (18 lb) with the compensation force gives a total down force of $19.4 \mathrm{lb}$ and $21 \mathrm{lb}$ for $80 \%$ and $100 \%$ machine speeds respectively.

Because the brush system in question had been tested at speeds below that of previous brush systems, it seemed evident that the observed arcing was not caused by excessive 
interface speed. One theory was that runout in the slip ring surfaces was "throwing" the brush pads off the slip ring surface (Fig. 4). The outer slip ring had a total indicated runout of $0.0015 \mathrm{in}$. and the inner slip ring had a runout of 0.0008 in. This might explain why the outer brushes were arcing and not the inner. The brush pad at the end of the strap has an approximate mass of $50 \mathrm{~g}$. Calculating a simple acceleration of this mass

$$
F=m a=m \frac{D x}{D t^{2}}
$$

where

$$
\begin{aligned}
m & =50 \mathrm{~g} \\
D x & =0.0015 \text { in. }=3.84 \times 10^{-5} \mathrm{~m} \text { (total runout) } \\
D t & =0.003 \mathrm{~s} \text { (approximate time frame for cycle) }
\end{aligned}
$$

gives a liftoff force of $0.21 \mathrm{~N}(0.047 \mathrm{lb})$. This is a very small force, which should have no effect on brush performance.

It was also suggested that the brushes were lifting after a discharge while there was still current flowing in the field coil circuit. At the end of a discharge, an explosively driven opening switch in the field coil circuit is actuated. The opening switch has a large $200 \mathrm{~m} \Omega$ stainless steel resistor bolted in parallel with the switch element. As the switch opens, the resistor is forced into the circuit and the increased resistance drags the field coil current down to zero. There is also a pressure switch on the brush actuation nitrogen supply line. The field coil current and brush pressure switch status are both instrumented and recorded during a normal discharge. After tests that had resulted in slip ring arcing, the brush pressure switch timing was checked. It was verified that the brushes had not lifted while there was still current in the field circuit.

\section{Field Measurements Within Brush Assembly}

Another theory was that axial field from the compulsator was interacting with the current in the brush straps, thus producing a $\mathrm{J} \times \mathrm{B}$ force either to lift a brush or to force it down. Because the brush straps have current flowing in opposite directions, this would explain why one brush set arcs and the other does not (Fig. 5). Prior to a full speed test, two Hall probes were placed at the end of the brush box to measure the axial field along the axis of the shaft. The Hall probes were connected to a signal conditioning unit that supplied the manufacturer's suggested bias current to the probes. The signal conditioning unit also amplified the output of the Hall probes prior to sending it to the data acquisition system. Magnetic orientation of the probes was verified using a Walker Scientific FGM-301 calibration unit. The calibration factors of the output amplifiers were also verified with a function generator prior to the test. The two probes measured field strengths of 0.048 and $0.046 \mathrm{~T}$ of axial field on the axis of the brush box. Using the formula

$F=I L B$

where

$$
I=\text { current }
$$

$L=$ length in meters

$B=$ field strength in Tesla

the applied force on the brushes can be determined. Using data from the full speed test where $\mathrm{I}=8,438 \mathrm{~A}(50,632 \mathrm{~A} / 6$ brushes), $\mathrm{L}=0.038 \mathrm{~m}$ (1.5 in.), and $\mathrm{B}=0.048 \mathrm{~T}$, the applied force on the brushes is $14.6 \mathrm{~N}$ (3.32 lb). With the measured $\mathrm{B}$ field direction and applying the right-hand rule, the outer brushes are indeed lifted by this force and the inner brushes are pushed down. This correlates with the observation that the outer brush set was the one arcing. While this force is small and only about 15 to $20 \%$ of the total applied downforce, it may be a contributing factor in the brush arcing.

\section{BRUSH SYSTEM UPGRADES}

As a result of the observed arcing and the design evaluation, it was concluded that the aluminum slip rings needed to be replaced with steel slip rings and the brushes needed to be actuated with a higher down force. The original design utilized aluminum slip rings to minimize weight as well as circuit impedance. Previous rotating machines at UTCEM had used steel slip rings with good success. The harder steel material provides a better sliding surface for the brush and also minimizes damage during small arc events.

The increase in downforce was required to compensate for any runout induced or field-induced lifting of the brushes. The original actuation pressure was set at 90 to $95 \mathrm{psi}$, which resulted in a down force of 17 to $18 \mathrm{lb}$. The brush system was upgraded to operate with about a twenty-five percent increase in down force, or about $23 \mathrm{lb}$.

A nested ring analysis showed that a new 4340 steel slip ring would have to be put on the copper shaft sub-conductor with 0.005 in. of radial interference to maintain several hundred psi pressure at peak machine speed. To fit this steel slip ring thermally on the shaft with several mils of clearance for assembly required a temperature delta of $550^{\circ} \mathrm{F}$ to $600^{\circ} \mathrm{F}$. The shaft conductors and insulators could not be chilled with water or ice due to the risk of introducing moisture into the assembly; therefore the slip ring had to be heated to $\sim 650^{\circ} \mathrm{F}$ to perform a thermal fit. This temperature was too high because the slip rings come in contact with composite shaft conductors, causing damage to the insulators. The need to exclude moisture precluded chilling the steel slip rings rapidly with water, and their thermal mass also prevented quick cooling with convective airflow.

A unique solution involved a two-layer slip ring using both aluminum and steel (Fig. 6). A sub-slip ring made of 7050T6 aluminum was thermally fit onto the shaft with only a slight radial interference ( $<0.002 \mathrm{in}$.). This was done at a lower temperature due to the light fit and higher thermal growth from the aluminum. The aluminum sub ring had a thin raised lip on its OD to act as a stop and a thermal barrier for the steel slip ring. This allowed the 4340 steel slip ring to be put on with a heavier $0.004 \mathrm{in}$. radial interference that required a $500^{\circ} \mathrm{F}$ temperature rise for a thermal fit. The raised lip on the aluminum sub-ring kept the hot steel ring 
from touching the composite insulators. The aluminum provided a thermal barrier just long enough to allow the steel ring to be cooled with convection cooling. The temperature of the composites was monitored with a handheld temperature probe and the temperatures never rose higher than $150^{\circ} \mathrm{F}$. The nested ring code was done for the two-layer slip ring design and assumed a $100^{\circ} \mathrm{F}$ temperature rise for both rings due to friction heating. The analysis concluded that both rings maintained several hundred psi compression during full speed operation.

The other brush upgrade involved operating the brush system at higher actuation pressure and down force. A pneumatically driven, molded rubber actuator is used to force the brush onto the slip ring. These injection-molded rubber bladders have been specifically designed for this use, but have shown a tendency to rupture if there is too much lateral strain during actuation. The bladders were designed to actuate in a linear motion to push the brush strap in a straight line. Lateral strain is defined as any movement by the bladder perpendicular to the actuation direction. Within the brush assembly, these rubber actuators are held in a G-10 composite housing that fits into the bend of the trailing arm brush strap geometry.

The original G-10 actuator housings were fabricated with a clearance of 0.030 to 0.040 in. around the outside of the bladder to make assembly easier. The actuator manufacturer suggested that this clearance be eliminated if the bladders were to be operated at higher pressures. A new two-piece G10 housing design was adopted that allowed the G-10 housing to be bounded around the actuator with $<0.005 \mathrm{in}$. of clearance. These new G-10 housing and actuator assemblies were fabricated and tested to demonstrate their performance. One of the new actuator assemblies and brush straps was set in a vice and positioned a short distance (0.06 in.) from a small force transducer. A high-pressure nitrogen bottle was connected to the actuator bladder via a small valve. The nitrogen pressure was set to $115 \mathrm{psi}$, which is about $25 \%$ over original operating pressure. The brush was actuated against the force transducer and an applied force of about $24 \mathrm{lb}$ was recorded.

This same assembly was actuated 1,000 cycles to fatigue test the new actuator design. The down force was checked every 100 cycles to see if the brush strap was yielding and thus changing the applied force. The force remained constant throughout the 1,000 cycles.

\section{CONCLUSIONS}

The brush system, which was designed for the model scale compulsator, performed well despite the small arcing events during higher speed runs. Data from the tests showed the arcs had no affect on machine performance, but were more an issue of maintenance and degraded brush performance over a long period of time. However, as interest in compulsators grows for a variety of applications, small problems such as arcing slip rings need to be understood. The discussed brush system upgrades remedied the problem and no additional arcing has been observed to date. The presence of the axial field in the brush assembly apparently was just strong enough to relieve some of the down force and cause a brush set to arc. This was easily fixed by increasing the mechanical down force slightly. This issue cautions designers of future rotating electrical pulsed machines to allow for stray fields in the brush gear that may inhibit the brush performance.

\section{REFERENCES}

[1] W. A. Walls, "High Speed, High Current Copper Finger Brushes for Pulsed Homopolar Generator Service,” IEEE Holm Conference on Electrical Contacts, September 30, 1985.

[2] J. H. Price, J. R. Kitzmiller, "Design of a Homopolar Generator for 400 $\mathrm{m} / \mathrm{s}$ Slip Ring Velocity Brush Testing," IEEE Transactions on Magnetics, Vol. Mag-22, No. 6, pp 1684-1689, Nov. 1986.

[3] Zenith Technical Bulletin, TB-1103, "Analysis of Contact Designs for High Withstand Current Ratings,” Zenith Controls Inc., Chicago, Ill. February 1976.

[4] H. B. Dwight, "Repulsion Between Strap Conductors," Engineer Canadian Westinghouse Company.

\section{FIGURE CAPTIONS}

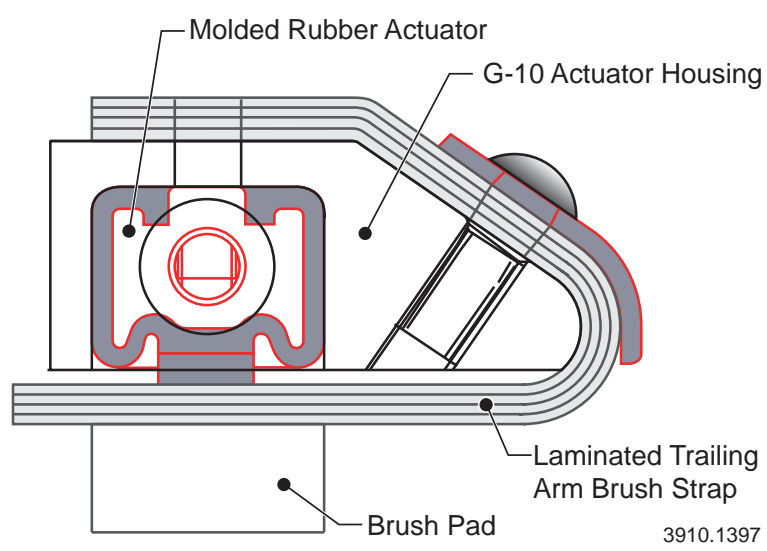

Figure 1. Trailing arm brush assembly

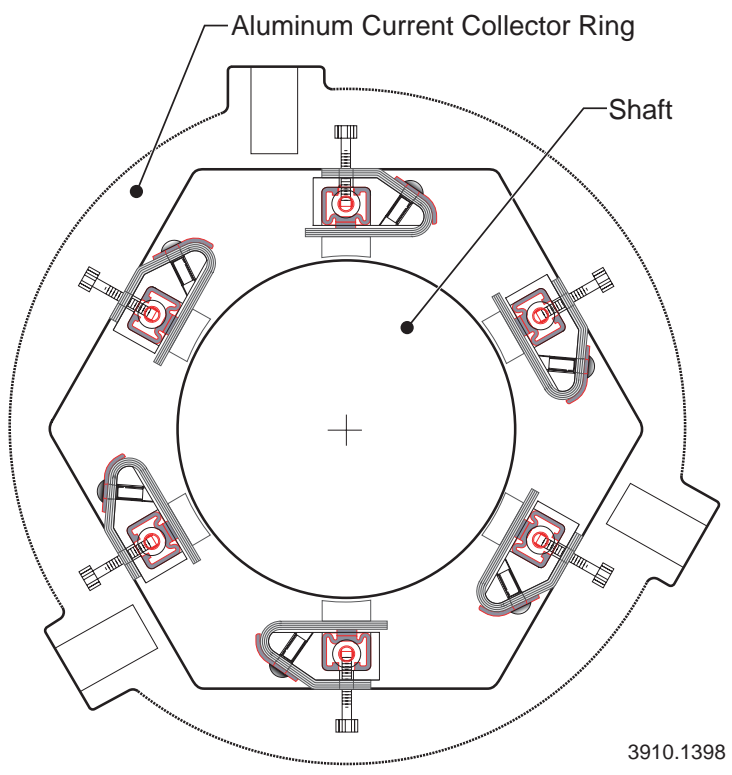


Figure 2. Brush arrangement on shaft of model scale compulsator

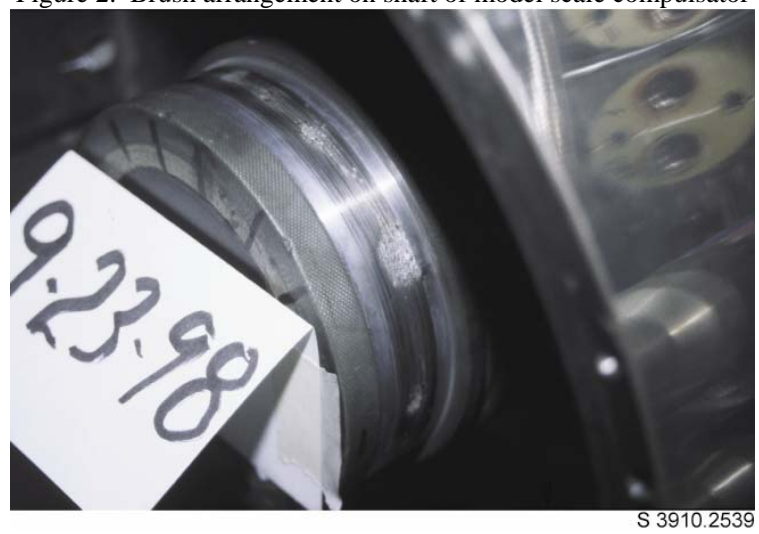

Figure 3. Arc marks observed on outer slip ring

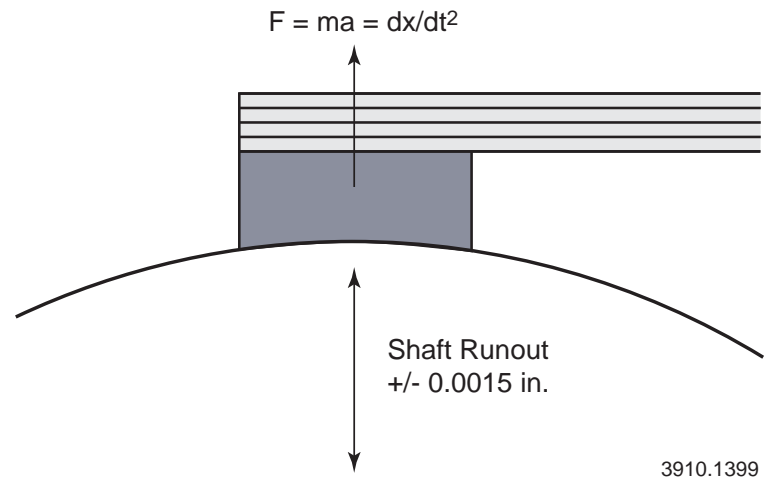

Figure 4. Runout force on brush pad

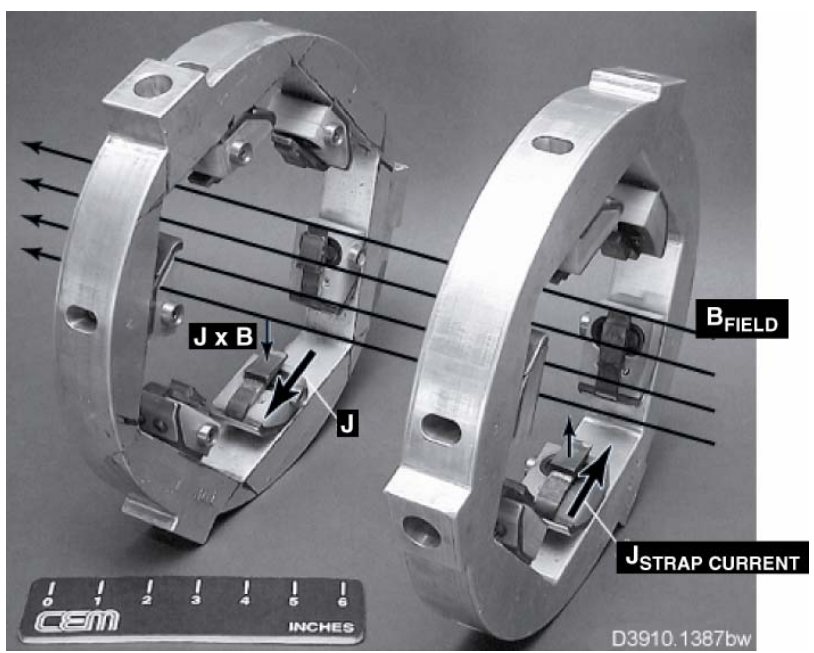

Figure 5. Field interaction with brush straps

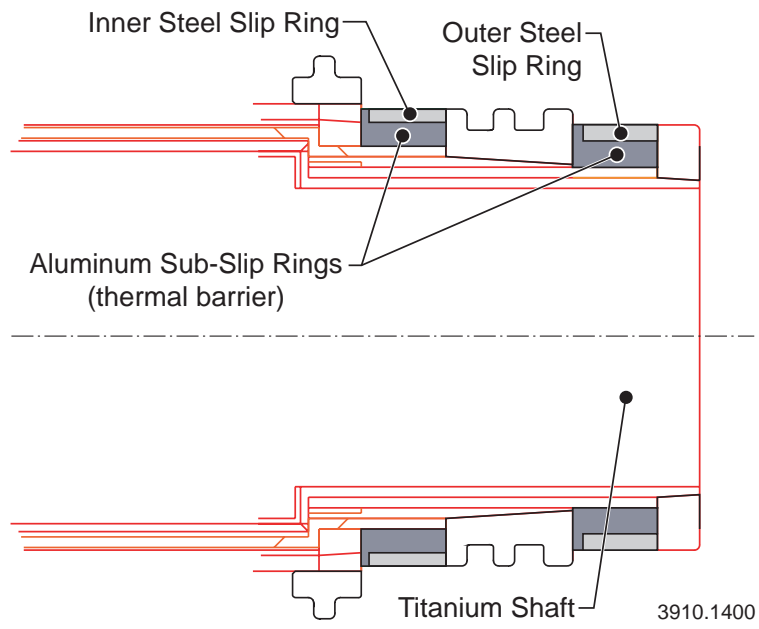

Figure 6. Modified slip ring design 